\title{
Effect of an Educational Intervention by Attendance and at Distance on Nurses' Knowledge about Pressure Ulcer
}

\author{
Elaine M. L. R. Andrade', Patrícia A. L. Cavalcanti' ${ }^{1}$, Ana Karoline C. Monteiro1, \\ Ana Karine C. Monteiro', Maria Helena B. A. Luz'1, José M. M. Neto', \\ Isabel A. C. Mendes ${ }^{2}$ \\ ${ }^{1}$ Nursing Department, Federal University of Piauí, Teresina, Brazil \\ ${ }^{2}$ Nursing Department, University of São Paulo, Ribeirão Preto, Brazil \\ Email: elairgel@gmail.com, patriciaazevedolc@yahoo.com.br, karolmonteiro2006@hotmail.com, \\ karinemonteiro2006@hotmail.com, mhelenal@yahoo.com.br, jose.machado.moita.neto@gmail.com \\ iamendes@eerp.usp.br
}

Received 10 August 2014; revised 3 September 2014; accepted 12 September 2014

Copyright (C) 2014 by authors and Scientific Research Publishing Inc.

This work is licensed under the Creative Commons Attribution International License (CC BY).

http://creativecommons.org/licenses/by/4.0/

(c) (i) Open Access

\section{Abstract}

The effect of an educational intervention by attendance and at distance on the knowledge of nurses about pressure ulcer (PU) was verified. An experimental research with a post-test control group was undertaken. A randomized sample of 43 nurses in a Control Group (CG) $(N=20)$ was submitted to an educational intervention by attendance and an Experimental Group (EG) ( $N=23$ ) was submitted to an intervention at distance. Data were collected between January and April 2012 in three phases, which were: location, invitation, registration and adaptation of the nurses to Moodle, educative intervention and post-test. The mean number of correct answers on the posttest among the nurses who participated in the intervention by attendance was $34.0(\mathrm{sd}=3.3)$, against $36.2(\mathrm{sd}=2.7)$ for the nurses in the distance education intervention. This difference in means was statistically significant $(p=0.019)$. The research evidenced that continuing education in nursing through distance education (DE) can be effective due to its practicality and interactivity and because it allows nurses in clinical practice to decide on the best time and place to access the content and improve their knowledge about PU.

\section{Keywords}

Pressure Ulcer, Distance Education, Nursing, Clinical Practice Guidelines 


\section{Introduction}

Pressure ulcers (PU) affect people all over the world (Hsu et al., 2013). Incidence levels in clinical practice are lower when the nurses are capable of assessing client risks and of planning and implementing appropriate interventions to prevent them (Magnan \& Maklebust, 2009).

Nevertheless, research shows that nurses' knowledge about the prevention of PU is still insufficient (Chianca et al., 2010; Iranmanesh et al., 2011; El Enein \& Zaghloul, 2011).

Educational interventions are an important tool to prevent PU and enhance nurses' knowledge about the topic (Jones, 2007; Cox et al., 2011; Tweed \& Tweed, 2008). Various teaching strategies have been used for continuing nursing education, including distance education (DE) (Jones, 2007).

The increase in educational interventions via $\mathrm{DE}$ is due to the fact that this teaching method allows health professionals to study without being obliged to leave their workplace or to spend their own financial resources for this purpose (Beeckman et al., 2008; Bigony, 2010).

Studies show that educational interventions by attendance and at distance are used for continuing nursing education (Jones, 2007; Cox et al., 2011; Beeckman et al., 2008; Ribeiro \& Lopes, 2006; Fernandes et al., 2008; Costa et al., 2009). Nevertheless, these studies do not reveal a consensus about the best teaching method for continuing nursing education purposes and, in Brazil, no studies have been published until date that have tested the effect of educational interventions by attendance and at distance on nurses' knowledge about PU.

In view of the above, the aim in this study was to verify the effect of an educational intervention by attendance and at distance on nurses' knowledge about PU.

\section{Methods}

Experimental study with a post-test control group, undertaken at a large Brazilian public hospital between January and March 2012.

The study population consisted of 178 nurses. A convenience sample of 60 nurses was selected according to the following exclusion criteria: being on holiday or medical leave at the time of data collection and not agreeing to participate in the educational intervention about PU, refusing to sign the Informed Consent Form (ICF).

After selecting the sample, the 60 nurses were randomly distributed in two groups. The Control Group (CG) $(\mathrm{N}=30)$ was submitted to an educational intervention by attendance and the Experimental Group (EG) $(\mathrm{N}=30)$ to an educational intervention at distance.

Participants were lost during the data collection and $(\mathrm{N}=20)$ and $(\mathrm{N}=23)$ nurses continued in the CG and EG, respectively, totaling 43. In this study, the causes of loss of nurses in the CG and EG were not examined. However, conducting educational interventions by attendance with health professionals while they provide assistance implies facing difficulties of physical displacement, lack of space for classes within a conception of on-site teaching and lack of motivation to take on new activities outside of work hours (Mendes et al., 2007). Likewise, the withdrawal of distance education interventions can be motivated by lack of time due to concentration of activities during the intervention period, problems with the computer and with the Internet provider (Ribeiro \& Lopes, 2006).

The aim of the educational intervention was to develop knowledge about PU and the content was organized in five classes: anatomy and skin physiology, scarring physiology, etiology and risk factors for the development of PU, PU staging and guidelines for PU prevention. The tutor, the content and the period of the intervention were the same for the CG and EG. The total hour load was 12 hours. For the CG, two hours were used to present the research objectives, invite the nurses to participate in the intervention and, in case of acceptance, to sign the ICF. Eight hours were dedicated at the oral presentation of the content, with the help of slides produced in Microsoft Office Power Point (2007) at the conference room of the institution. The oral presentation was repeated in all work shifts (Morning, Afternoon and Night) so as to offer different time options to the nurses. The remaining two hours served to apply the knowledge test about PU. In the EG, two hours by attendance served to present the research objectives, invite the nurses to participate and, in case they accepted, sign the ICF and get adapted to the Virtual Learning Environment (VLE) Moodle. Eight hours were used to study the content, which was available in Moodle throughout the intervention. The two final hours corresponded to the application of the knowledge test about PU.

The data collection instrument contained sociodemographic characteristics, educational, professional, computer and Internet use data and the knowledge test about PU. This test was developed by Pieper \& Mott (1995) 
and adapted to Portuguese by Caliri, Miyazaki \& Pieper (2003). The test has 41 statements about PU, six related to classification (1, 6, 9, 20, 33 and 38), two related to description (31 and 32) and the others to prevention of PU. For each statement the nurses elected one answer considering the options: True (T), False (F) or Do Not Know (DN). The total score was obtained by the sum of the correct answers on the test. The knowledge level was considered appropriate in case of $90 \%$ or more of correct answers on the test items (Pieper \& Mattern, 1997).

The data were collected in three phases, as follows: in the first phase, the researcher and two Scientific Initiation students worked in shifts (Morning, Afternoon and Night) to locate the 178 nurses who worked at the institution. When they located the possible study participants, the researcher and the two students presented the research objectives, clarified that the groups to participate in the educational intervention would be drafted, so that the participant could be part of the CG or EG; invited them to participate and, if they accepted, got the nurses' signature on the ICF and requested a contact e-mail address. After selecting the study participants, the groups were drafted and posters with this distribution were hung in all sectors of the institution, so that the participants would know what group they would belong to. The EG participants were registered in Moodle and received a login and password by e-mail. To guarantee these participants' adaptation to Moodle, the researcher and the students held a training program during two weeks on how to access and navigate in this environment. Next, the CG and EG were submitted to an educational intervention and, in the third phase, the post-test was applied to verify the nurses' knowledge about PU after the educational intervention.

The data were analyzed in Statistical Package for Social Sciences Version 18.0 (SPSS Version 18.0). Descriptive statistics were used to analyze the sociodemographic, educational, professional, computer and Internet use variables and the nurses' knowledge about PU. To verify the difference between the CG and EG in terms of sociodemographic, educational, professional, computer and Internet usage characteristics, the Chi-square test or Fisher's Exact test were used for qualitative variables. Fisher's Exact test was used when $20 \%$ of the cells had an expected value below five. When the variables were quantitative, the $t$ Test for two independent samples was used and, when the normality premise was violated, the Mann-Whitney test was used. The $t$ Test for two independent samples was also used to check for knowledge differences about PU between the CG and EG. Test results with $\alpha$ inferior or equal to 0.05 were considered statistically significant. Approval for the research was obtained from the Research Ethics Committee under protocol 0416.0.045.000-11.

\section{Results}

Forty-three nurses participated in the study, 20 (46.5\%) in CG and 23 (53.5\%) in EG. The nurses had similar characteristics, with a statistically significant difference for the gender variable only $(p=0.050)$. The majority $35(81.4 \%)$ was female and the mean age was 36.4 (sd = 10.4) for the CG and 31.2 (sd = 7.3) for the EG. Only one (5\%) nurse in the CG held a Master's degree. In the Control and Experimental Groups, 42 (97.7\%) nurses had a computer. More than half of the nurses, 30 (69.8\%) used the computer daily and 36 (85.7\%) at home. All of the nurses, 43 (100\%), had access to the Internet. Twenty-nine (67.4\%) of them used the Internet daily, 38 (88.4\%) at home. A statistically significant difference was found in the knowledge about PU among the nurses in the CG and EG ( $p=0.019)$ Table 1.

\section{Discussion}

In this study, a statistically significant difference was found in the knowledge about PU between the CG and EG ( $p=0.019$ ). This result goes against Brazilian and international study results (Cox et al., 2011; Beeckman et al., 2008; Padalino \& Peres, 2007, Horiuchi et al., 2009, Khatony et al., 2009; Abbaszadeh et al., 2011; Haney et al., 2012).

In Florida, a randomized controlled study compared conventional lectures with tele-education for the purpose of wound care teaching and the results showed no significant difference in any category on the practical skills test and in the written test results (Haney et al., 2012).

In Tokyo, researchers assessed a graduate nursing program at distance and did not observe a difference in post-test scores between the learning groups at distance and by attendance (Horiuchi et al., 2009).

In Kerman, Iran, in a quasi-experimental study, the effect of two teaching methods (e-learning and lectures) were compared and the differences in competency acquisition for documentation were analyzed between nurses who participated in e-learning $(\mathrm{N}=30)$ and nurses in the lecture group $(\mathrm{N}=31)$. The study results indicated no 
Table 1. Knowledge about PU after educational intervention.

\begin{tabular}{cccc}
\hline \multirow{2}{*}{ Group } & \multicolumn{3}{c}{ Knowledge about PU after intervention } \\
\cline { 2 - 4 } & $\bar{x}$ & sd & $p$ \\
\hline Control & 34.0 & 3.3 & $0.019^{*}$ \\
\hline Experimental & 36.2 & 2.7 & \\
\hline Note: $\bar{x}$ - mean; sd-standard deviation; ${ }^{*} t$ Test. &
\end{tabular}

statistically significant difference between the two groups (Abbaszadeh et al., 2011).

In Tehran, also in Iran, researchers compared the effectiveness of teaching methods through the World Wide Web (web) and by attendance on nurses' knowledge about AIDS (Acquired Immunodeficiency Syndrome). The results showed that there was no significant difference between the groups and that the web-based method seems to be as effective as the method by attendance for the sake of continuing nursing education (Khatony et al., 2009).

In Brazil, researchers compared the knowledge learned between the groups of nurses who used e-learning and who received training by attendance at a Hospital and Maternity in São Paulo. The results demonstrated that the two groups learned the knowledge equivalently, concluding that the two methods were effective (Padalino \& Peres, 2007).

In this study, some factors may have contributed to the stronger effect of the online educational intervention on the knowledge about PU when compared to the method by attendance. One of them was that the nurses in the CG did not attend the training classes regularly. Another factor was the flexibility and independence resulting from the online educational intervention, granting the EG access to the intervention at any time and place and as many times as they wanted.

The effect of the educational intervention by attendance and at distance on the knowledge is not different in most of the studies cited earlier. Nevertheless, the conclusions of all of these studies indicate the online educational intervention as a more effective strategy to reach people who want or need further qualification but who, for different reasons, cannot be absent from their daily life and work context (Cox et al., 2011; Padalino \& Peres, 2007; Horiuchi et al., 2009; Khatony et al., 2009; Abbaszadeh et al., 2011; Haney et al., 2012).

This study came with limitations related to the sample size, which impedes the generalization of the results; the nurses' lack of attendance to the educational intervention classes and the limited use of synchronous and asynchronous communication tools in Moodle, which may have turned the nurses' learning solitary.

\section{Conclusion}

In conclusion, the knowledge about PU among nurses who participated in the online educational intervention was greater than that in the intervention by attendance.

\section{References}

Abbaszadeh, A., Sabeghi, H., Borhani, F., \& Heydari, A. (2011). A Comparative Study on Effect of e-Learning and Instructor-Led Methods on Nurses’ Documentation Competency. Iranian Journal of Nursing and Midwifery Research, 16, 235243.

Beeckman, D., Schoonhoven, L., Boucqué, H., Van Maele, G., \& Defloor T. (2008). Pressure Ulcers: e-Learning to Improve Classification by Nurses and Nursing Students. Journal of Clinical Nursing, 17, 1697-1707. http://dx.doi.org/10.1111/j.1365-2702.2007.02200.x

Bigony, L. (2010). Can You Go the Distance? Attending the Virtual Classroom. Orthopaedic Nursing, 29, 390-392. http://dx.doi.org/10.1097/NOR.0b013e3181f8380a

Caliri, M. H. L., Miyazaki, M. Y., \& Pieper, B. (2003). Knowledge about Pressure Ulcers by Undergraduate Nursing Students in Brazil. Ostomy Wound Manage, 49, 4-63.

Chianca, T. C., Resende, J. F., Borges E. L., Nogueira, V. L., \& Caliri, M. H. L. (2010). Pressure Ulcer Knowledge among Nurses in a Brazilian University Hospital. Ostomy Wound Management, 56, 58-64.

Costa, J. B., Peres, H. H. C., Rogenski, N. M. B., \& Baptista, C. M. C. (2009). Proposta educacional on-line sobre úlcera por pressão para alunos e profissionais de enfermagem. Acta Paulista de Enfermagem, 22, 607-611. 
http://dx.doi.org/10.1590/S0103-21002009000500002

Cox, J. R., Roche, S., \& Van Wynen, E. (2011). The Effects of Various Instructional Methods on Retention of Knowledge about Pressure Ulcer among Critical Care and Medical-Surgical Nurses. The Journal of Continuing Education in Nursing, 42, 71-78. http://dx.doi.org/10.3928/00220124-20100802-03

El Enein, N. Y. A., \& Zaghloul, A. A. (2011). Nurses’ Knowledge of Prevention and Management of Pressure Ulcer at a Health Insurance Hospital in Alexandria. International Journal of Nursing Practice, 17, 262-268. http://dx.doi.org/10.1111/j.1440-172X.2011.01933.x

Fernandes, L. M., Caliri, M. H. L., \& Haas, V. J. (2008). Efeito de Intervenções Educativas no conhecimento dos profissionais de enfermagem sobre prevenção de úlceras por pressão. Acta Paulista de Enfermagem, 21, 305-311.

Haney, M., Silvestri, S., Van Dillen, C., Ralls, G., Cohen, E., \& Papa, L. (2012). Comparison of Tele-Education versus Conventional Lectures in Wound Care Knowledge and Skill Acquisition. Journal of Telemedicine and Telecare, $18,79-81$. http://dx.doi.org/10.1258/jtt.2011.110811

Horiuchi, S., Yaju, Y., Koyo, M., Sakyo, Y., \& Nakayama, K. (2009). Evaluation of a Web-Based Graduate Continuing Nursing Education Program in Japan: A Randomized Controlled Trial. Nurse Education Today, 29, 140-149. http://dx.doi.org/10.1016/j.nedt.2008.08.009

Hsu, M., Tsao, W., \& Sung, H. C. (2013). The Effectiveness of Educational Programs in Promoting Nurses' Knowledge of Pressure Ulcers: A Systematic Review Protocol. The JBI Database of Systematic Reviews and Implementation Reports, 11, 132-139.

Iranmanesh, S., Rafiei, H., \& Foroogh Ameri, G. (2011). Critical Care Nurses’ Knowledge about Pressure Ulcer in Southeast of Iran. International Wound Journal, 8, 459-464. http://dx.doi.org/10.1111/j.1742-481X.2011.00817.x

Jones, M. L. (2007). E-Learning in Wound Care: Developing Pressure Ulcer Prevention Education. British Journal of Nursing, 16, S26-S31. http://dx.doi.org/10.12968/bjon.2007.16.Sup3.24529

Khatony, A., Nayery, N. D., Ahmadi, F., Haghani, H., \& Vehvilainen-Julkunen, K. (2009). The Effectiveness of Web-Based and Face-to-Face Continuing Education Methods on Nurses' Knowledge about AIDS: A Comparative Study. BMC Medical Education, 9, 41-47. http://dx.doi.org/10.1186/1472-6920-9-41

Magnan, M. A., \& Maklebust, J. (2009). The Nursing Process and Pressure Ulcer Prevention: Making the Connection. Advances in Skin \& Wound Care, 22, 83-92. http://dx.doi.org/10.1097/01.ASW.0000345279.13156.d0

Mendes, I. A. C., Godoy, S., Silva, E. C., Seixas, C. A., Nogueira, M. S., \& Trevizan, M. A. (2007). Educación permanente para profesionales de salud: Mediación tecnológica y surgimiento de valores y cuestiones éticas. Enfermería Global, 6, $1-8$.

Padalino, H., \& Peres, H. C. (2007). E-Learning: Estudo comparativo da apreensão do conhecimento entre enfermeiros. Revista Latino-Americana de Enfermagem, 15, 397-403. http://dx.doi.org/10.1590/S0104-11692007000300006

Pieper, B., \& Mattern, J. C. (1997). Critical Care Nurse’ Knowledge of Pressure Ulcer Prevention, Stating and Description. Ostomy/Wound Management, 43, 22-31.

Pieper, B., \& Mott, M. (1995). Nurse’s Knowledge of Pressure Ulcer Prevention, Stating, and Description. Advances in Wound Care, 8, 34-48.

Ribeiro, M. A. S., \& Lopes, M. H. B. M. (2006). Desenvolvimento, aplicação e avaliação de um curso à distância sobre tratamento de feridas. Revista Latino-Americana de Enfermagem, 14, 77-84. http://dx.doi.org/10.1590/S0104-11692006000100011

Tweed, C., \& Tweed, M. (2008). Intensive Care Nurse’s Knowledge of Pressure Ulcers: Development of an Assessment Toll and Effect of an Educational Program. American Journal of Critical Care, 17, 338-346. 
Scientific Research Publishing (SCIRP) is one of the largest Open Access journal publishers. It is currently publishing more than 200 open access, online, peer-reviewed journals covering a wide range of academic disciplines. SCIRP serves the worldwide academic communities and contributes to the progress and application of science with its publication.

Other selected journals from SCIRP are listed as below. Submit your manuscript to us via either submit@scirp.org or Online Submission Portal.
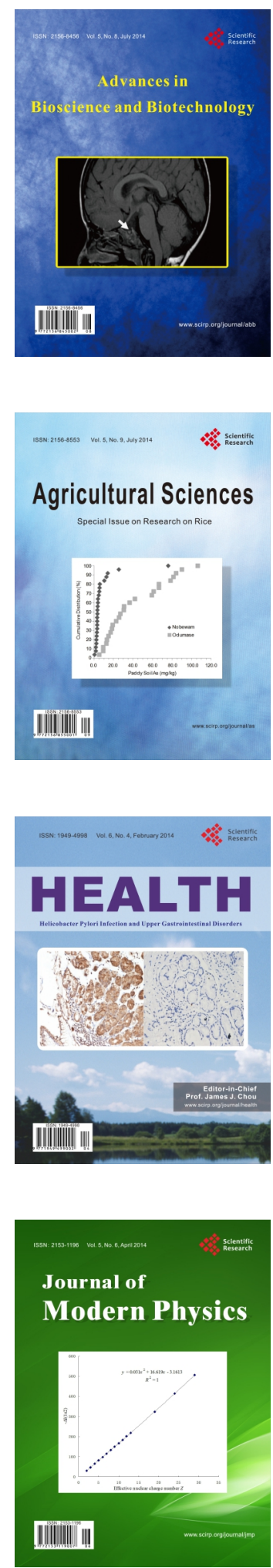
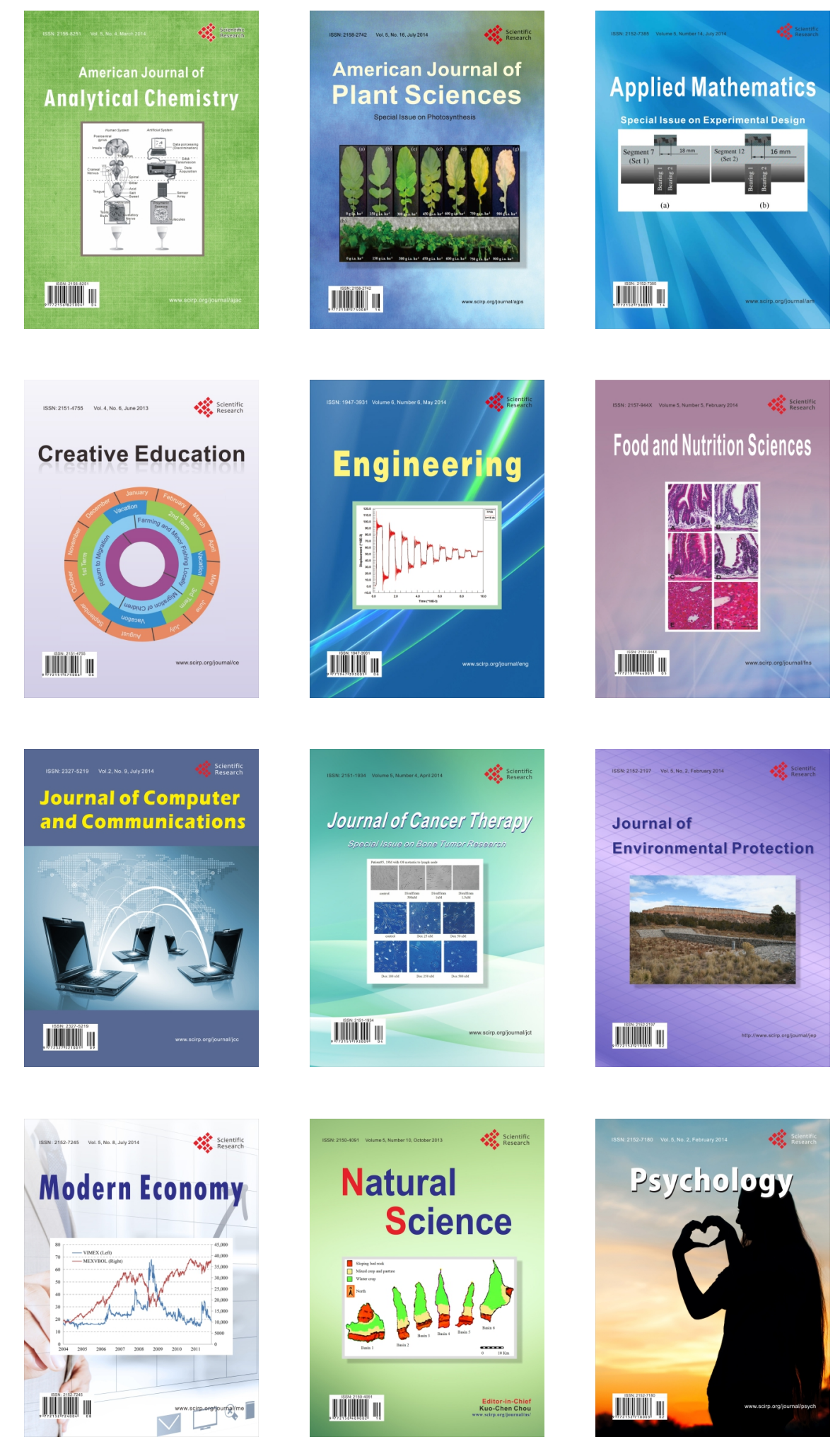